\title{
EDUCATION AND TRAINING Including medical students in quality improvement projects in primary care
}

\author{
Authors: Luamar Dolfini, ${ }^{A}$ Gabriella Williamson ${ }^{B}$ and Pippa Oakeshott ${ }^{C}$
}

\begin{abstract}
We share our experience as medical students who have recently completed quality improvement projects in primary care. We have found that quality improvement projects, such as audits, are mutually beneficial for clinicians who may need to conduct annual appraisals and students who benefit from the educational experience.
\end{abstract}

KEYWORDS: Students, primary care, education, audit

DOI: $10.7861 /$ fhj.2019-0049

The October 2019 edition of the Future Healthcare Journal focused on education. ${ }^{1}$ This included the successful quality improvement project by Dormandy et al on increasing the use of the 4 AT delirium screening tool. ${ }^{2}$

We would like to share our experience of a medical student quality improvement project in primary care. In response to the National Institute for Health and Care Excellence (NICE) guidelines for sepsis assessment in children published in 2013, we completed an audit cycle investigating the assessment of children aged $<5$ years presenting with fever $\left(>37.5^{\circ} \mathrm{C}\right)$ at an inner-city general practice. ${ }^{3}$

Investigating febrile illness is important as early recognition of sepsis reduces mortality and morbidity. ${ }^{4}$ The 2013 NICE guideline outlines four signs that should be recorded: temperature, pulse, respiratory rate and capillary refill time (CRT). ${ }^{3}$

Our first audit in 2018 looked at general practitioners' compliance by analysing the computerised records of 111 consultations with feverish children from May 2014 - May 2018. Table 1 shows all four signs were recorded in only $11 \%$ (12/111) of all consultations.

These results were presented to the general practitioners and practice nurses in a weekly clinical meeting in 2018. Not everyone was aware of the NICE guidelines. In addition, CRT was not a commonly used sign when the older clinicians were trained. Everyone agreed to improve recording of signs.

Authors: Amedical student, St George's, University of London, London, UK; 'B medical student, St George's, University of London, London, UK; ' 'professor of general practice, St George's, University of London, London, UK

\section{Table 1. Percentage of signs and symptoms}

recorded in audit 1 and audit 2

Signs needed Audit 1: percentage

for the NICE of 111 consultations

Audit 2: percentage of

traffic light

system

before June 2018

recording each sign

48 consultations after

June 2018 recording

Temperature

$100 \%$

each sign

Pulse

$81 \%$

$100 \%$

Respiratory $\quad 49 \%$

rate

$49 \%$

$94 \%$

Capillary refill $\quad 32 \% \quad 50 \%$

time

All four signs $\quad 11 \% \quad 25 \%$

In audit 1 , the mean age of children was 18 months (range 2-53 months) with the highest temperature recording $40^{\circ} \mathrm{C}$. In audit 2 the mean age was 21 months (range 12-48 months) with the highest temperature recording $40.6^{\circ} \mathrm{C}$.

A re-audit was undertaken assessing 48 consecutive consultations from June 2018 - June 2019. Only 25\% (12/48) of consultations had all four signs recorded, an overall improvement of just $14 \%$.

These findings were presented again at a practice meeting in November 2019. Clinicians said the main reason for such a small improvement was probably that many febrile children seen by general practitioners are not particularly ill. If a child seemed well, was drinking, alert and active, they would not necessarily record all the signs, especially within the constraints of a 10-minute consultation. It would be different if the child was unwell and they were considering referral to paediatric emergency department. ${ }^{5}$ EMIS computerised general practitioner records now have a red 'sepsis' prompt which pops up if abnormal clinical signs, such as high fever and tachycardia, are recorded in a template.

As students, this was exciting as we were able to contribute to a change in clinical practice. Involving medical students in quality improvement projects can be mutually beneficial for clinicians who need audits for their annual appraisals and for students who benefit from the educational experience.

\section{Acknowledgements}

The authors thank the doctors, nurses, staff and patients at the Curran practice, Manor Health Centre, London, UK. 


\section{References}

1 Fox K. Education means learning what works and what doesn't. FHJ 2019;6:149-50.

2 Dormandy L, Mufti S, Higgins E, Bailey C, Dixon M. Shifting the focus: A QI project to improve the management of delirium in patients with hip fracture. FHJ 2019;6:215-9.

3 National Institute for Health and Care Excellence. Fever in under 5s: assessment and initial management: Clinical guideline [CG160]. NICE, 2018. www.nice.org.uk/guidance/cg160
4 Gauer RL. Early recognition and management of sepsis in adults: the first six hours. Am Fam Physician 2013;88:44-53.

5 National Institute for Health and Care Excellence. Fever in under 5s: assessment and initial management: NICE guideline [NG143]. NICE, 2019. www.nice.org.uk/guidance/ng143

Address for correspondence: Luamar Dolfini, Population Health Research Institute, St George's, University of London, London SW17 ORE, UK.

Email: m1503711@sgul.ac.uk

\section{A new Clinical Medicine and Future Healthcare Journal subject collection}

Articles relating to the COVID-19 pandemic are now gathered together in one handy online subject collection for you to browse.

Browse the collection: www.rcpjournals.org/covid-19 
Never too

busy to learn

\section{How the modern team can learn}

\section{together in the busy workplace}

High-quality learning opportunities are essential for clinicians in training, both for the successful completion of their training and to ensure high standards of care in the NHS.

Published by the Royal College of Physicians in 2018 and supported by Health Education England, Never too busy to learn helps healthcare teams make the most of daily learning opportunities in the workplace.

It explores how 'invitational' learning environments can be created in clinical settings and seeks to answer two key questions:

> How do we create learning opportunities in the clinical workplace?

$>$ How do we maximise the impact of these opportunities?

Never too busy to learn includes case studies that demonstrate tested strategies and explore how to maximise the learning opportunities present within the flow of everyday clinical work.

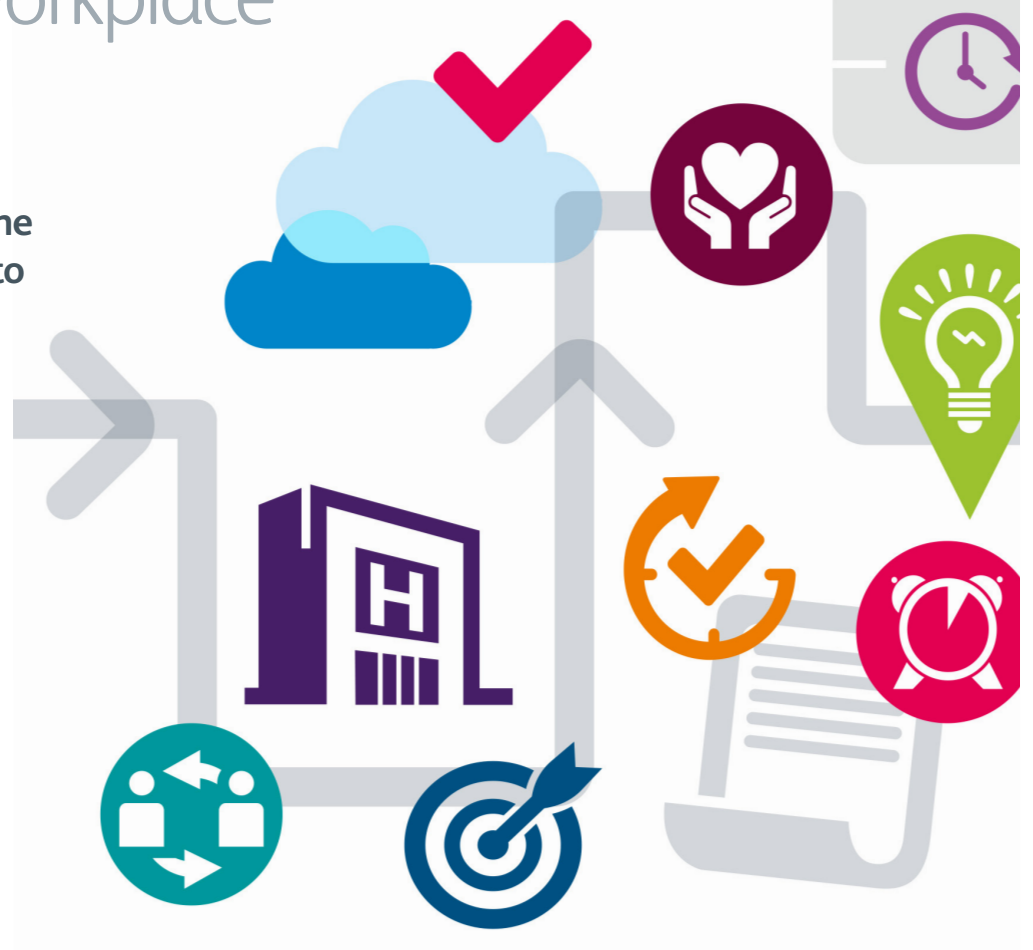

Download the report: www.rcplondon.ac.uk/never-too-busy-to-learn

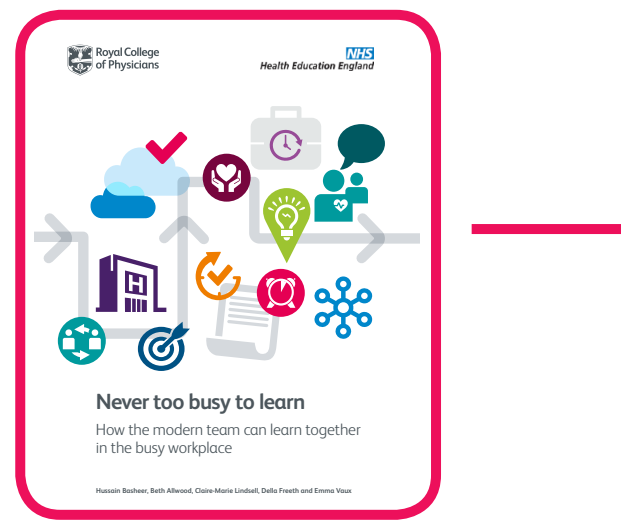

